\title{
DESIGN AND PERFORMANCE ANALYSIS OF UWB CIRCULAR RING ANTENNA WITH DEFECTED GROUND STRUCTURE
}

\author{
Neha Tanzeem Sagar ${ }^{1}$, M. L. Meena ${ }^{2}$ and Pankaj Shukla ${ }^{3}$ \\ Department of Electronics Engineering, Rajasthan Technical University, India
}

\begin{abstract}
A compact circular ring antenna with defected ground structure (DGS) has been design for Ultra-Wide Band (UWB) applications. Initially, a circular patch antenna is design by introducing a rectangular DGS structure. Further, slot has been inserted in circular patch to improve the impedance bandwidth. The proposed design covers the frequency range of 2.4-10.4GHz below -10dB. Proposed antenna has design and fabricated on FR-4 substrate having $1.5 \mathrm{~mm}, 4.3$ thickness and dielectric constant, respectively. The performance of the designed antenna is analyzing with optimized dimensions in terms of return loss, VSWR, radiation pattern, gain characteristics, group delay and surface current distributions. Further, performance analysis of the proposed antenna has also been compared with existing suggested antennas in literature with compact in size. The fabricated antenna shows a good result with simulations software.
\end{abstract}

Keywords:

Circular Ring, Defected Ground Structure, Fractional Bandwidth, Micro-Strip, Ultra-Wideband

\section{INTRODUCTION}

The demand of UWB antenna is increases day by day in the wireless communication system due to high data rate. Different techniques and applications are operated on UWB frequency spectrum, using ultra short pulses in the order of nanoseconds [1].

Several UWB antennas are designed by different shapes of patch or radiating elements like square, circular, ring, elliptical, pentagonal, hexagonal [2]-[10]. To improve the bandwidth of antenna different defected ground planes are reported by several authors [11] [12]. Further, using different shapes of DGS or slots in ground and patch can also enhance the bandwidth, gain and directivity [13]-[15]. The comparative performance of different wideband antennas is reported by several authors with impedance bandwidth and gain characteristics due to their compact structure using DGS [16]-[19].

To increase the radiated power, the directional antennas are designed by the several researchers. Due to regular or symmetrical defected ground structures and radiating elements gives the directional characteristics of antennas [20]. Directional antenna is used to radiate the power to increase the performance of the antenna. There are many directional UWB antenna has also been designed with different patch and partial ground plane. Further, wide band antennas were designed with for the frequency range of 3.1-10.6GHz using square, circular, ring and rectangular slots in patch as well as ground plane [21] [22]. Recently, UWB circular antenna is design using fuzzy approach but size of the antenna is large [23]. Further, recently Patil et al. [31] proposed the UWB antenna having size $108 \times 108 \mathrm{~mm}^{2}$, but the fractional bandwidth and frequency band of the antenna are much smaller.
In this work, a compact circular ring UWB antenna with slotted ground has been presented for the applications of medical imaging and wall penetration. Design antenna achieves 2.4$10.4 \mathrm{GHz}$ UWB band with five resonant frequencies of 2.8, 4.5, $6.4,8.2$ and $9.4 \mathrm{GHz}$, which attain $125 \%$ fractional bandwidth. The proposed antenna improves the fractional bandwidth, gain and directive radiation pattern when compared with existing reported work in literature [22]-[24], [29]-[31]. Hence, the design antenna is useful for wall imaging and radar system.

The presented works are organized as following sections. Section 2 elaborates antenna design, section 3 have comparative parametric analysis, section 4 have measured result and discussion and finally conclusion of the paper is done in section 5 .

\section{PROPOSED DESIGN}

A circular patch antenna is designed by the arrangement of partial slotted ground structure and circular ring patch as shown in Fig.1. A circular ring antenna consist an outer and inner radius $R_{1}$ and $R_{2}$, respectively. It has been fabricated on FR-4 substrate with dielectric constant of $\epsilon_{r}=4.3$. The length and width of the antenna are $L=50 \mathrm{~mm}$ and $W=42 \mathrm{~mm}$, respectively. On the back side of the substrate a partial ground plane is kept having length and width are $L_{g}=20 \mathrm{~mm}, W=W_{g}=42 \mathrm{~mm}$, respectively. The width of micro-strip line is fixed on $W_{f}=2 \mathrm{~mm}$ to achieve well impedance matching. The length of feed line is $L=L_{g}+h=$ $20.8 \mathrm{~mm}$ which is a combination of ground length and feed gap. Further, to achieve better impedance bandwidth the inner radius $R_{2}$ is inserted in circular patch. The simulation is done by software Electromagnetic (EM) simulator.

The inner and outer radius of the proposed antenna are calculated based on equations [28].

$$
\begin{gathered}
R_{1}=\frac{58 \times 10^{9}}{f_{r} \sqrt{\epsilon_{\text {reff }}}} \\
R_{2}=0.30 R_{1}
\end{gathered}
$$

where, $R_{1}$ and $R_{2}$ are outer and inner radius, respectively, $f_{r}$ is resonant frequency of antenna, and $\varepsilon_{\text {reff }}=\sqrt{\frac{\epsilon_{r}+1}{2}}$ effective dielectric constant of substrate. The lowest resonant frequency of the proposed design is $2.8 \mathrm{GHz}$. The detailed design parameters of circular ring antenna are given in Table.1. 


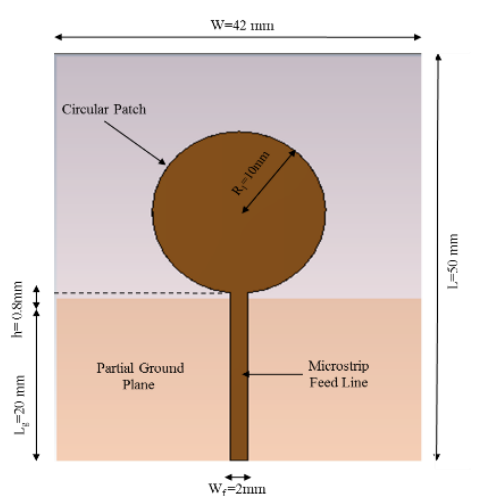

(a)

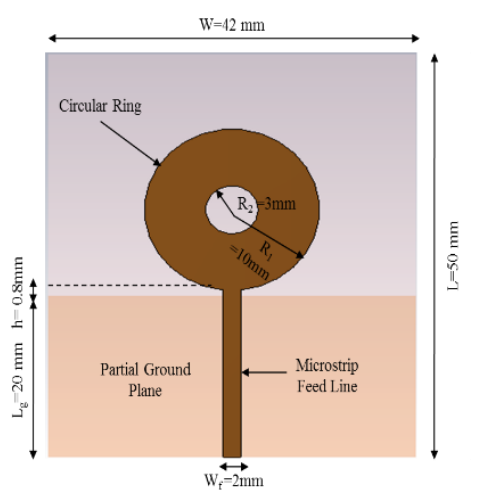

(b)

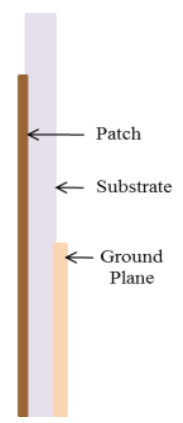

(c)

Fig.1. Geometry of (a) circular disc antenna (b) proposed circular ring antenna; (c) side view of structure

Table.1. Design Parameters of the Antenna

\begin{tabular}{|c|c|c|}
\hline Parameters & Description & $\begin{array}{c}\text { Dimensions } \\
(\mathbf{m m})\end{array}$ \\
\hline$L$ & Length of Antenna & 50 \\
\hline$W$ & Width of Antenna & 42 \\
\hline$h_{s}$ & Height of Dielectric Substrate & 1.5 \\
\hline$L_{g}$ & Length of Ground & 20 \\
\hline$W_{g}$ & Width of Ground & 42 \\
\hline$W_{f}$ & Width of MS Feed line & 2 \\
\hline$L_{f}$ & Length of MS Feed line & 20.8 \\
\hline
\end{tabular}

\begin{tabular}{|c|c|c|}
\hline$R_{1}$ & Outer Radius of Patch & 10 \\
\hline$R_{2}$ & Inner Radius of Patch & 3 \\
\hline$h$ & $\begin{array}{c}\text { Height of Feed Gap between } \\
\text { Ground and Feed line }\end{array}$ & 0.8 \\
\hline
\end{tabular}

\section{COMPARATIVE PARAMETRIC ANALYSIS}

\subsection{RETURN LOSS $\left(S_{11}\right.$ dB $)$ VARIATION}

The parametric analysis has been carried out by varying radius of circular patch $\left(R_{1}, R_{2}\right)$, feed width $\left(W_{f}\right)$ and separation between ground plane and circular patch and width of ground of two different designs as shown in Fig.1.The comparative return loss variation of circular disc and ring antennas are shown in Fig.2. A circular disc antenna bandwidth can be enhanced by inserting a slot in radiating patch. As seen in Fig.2, the bandwidth of a disc antenna is obtaining $2.6-10.3 \mathrm{GHz}$ below $-10 \mathrm{~dB}$. The return loss variations are calculated $-15.4 \mathrm{~dB},-31.2 \mathrm{~dB},-13.2 \mathrm{~dB},-18.7 \mathrm{~dB}$,$17.2 \mathrm{~dB}$ at $2.8 \mathrm{GHz}, 4.7 \mathrm{GHz}, 6.5 \mathrm{GHz}, 8 \mathrm{GHz}, 9.6 \mathrm{GHz}$ resonant frequency, respectively. Further to improve the bandwidth of antenna, a circular slot of radius $R_{2}$ is $3 \mathrm{~mm}$ has been introduced in radiating patch. By inserting a slot, lower cut off frequency $2.6 \mathrm{GHz}$ is slightly shifted to $2.4 \mathrm{GHz}$ and higher cut off frequency $10.3 \mathrm{GHz}$ is shifted to $10.4 \mathrm{GHz}$ and frequency band of $2.4-$ $10.4 \mathrm{GHz}$ has been obtained at $2.8 \mathrm{GHz}, 4.5 \mathrm{GHz}, 6.4 \mathrm{GHz}, 8.2 \mathrm{GHz}$ and $9.4 \mathrm{GHz}$ resonance frequencies. The fractional bandwidth of proposed design achieves $125 \%$, whereas fractional bandwidth of the reference antenna is $119 \%$. Therefore, proposed antenna is suitable for radar, medical imaging, wall imaging and ground penetrating.

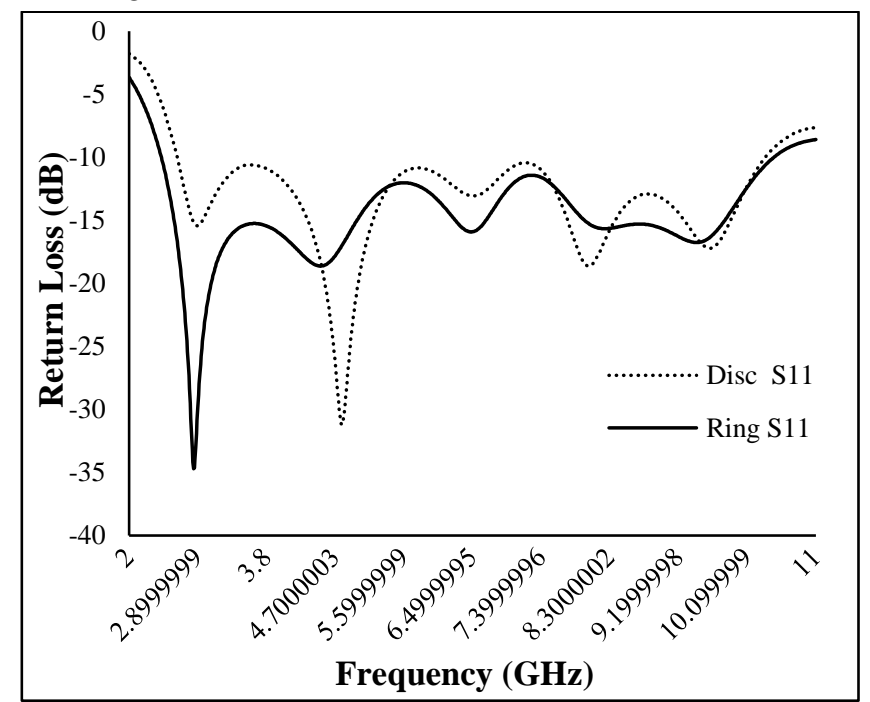

Fig.2. Simulated return loss $\left(S_{11} \mathrm{~dB}\right)$ plots of circular disc and circular ring UWB antenna

\subsubsection{Return loss variation with outer radius $\left(R_{1}\right)$ and inner radius $\left(\boldsymbol{R}_{2}\right)$ :}

The comparative return loss variation for circular disc and circular ring antenna has been shown in Fig.3. It can be observed that the impedance matching has been poor at $R_{1}=10 \mathrm{~mm}$ for circular disc between $3-4 \mathrm{GHz}$ frequency also the higher cut off frequency is shifted towards lower side. Whereas the impedance 
bandwidth has been improving at the same dimensions of the outer radius for circular ring antenna. Therefore, impedance bandwidth achieves $125 \%$ in the band of $2.4-10.4 \mathrm{GHz}$. Also impedance matching has been improving in entire specified UWB band by inserting a ring slot in the patch. Hence, the optimized dimensions have been chosen for outer and inner radius $R_{1}=$ $10 \mathrm{~mm}$ and $R_{2}=3 \mathrm{~mm}$, respectively as can be seen in Fig. 3 and Fig.4.

\subsubsection{Return loss variation with micro-strip feed width $\left(W_{f}\right)$ :}

The effect of feed width on return loss are shown in Fig.5 for circular disc and circular ring antenna. It can be observed that by increasing the value of feed width the lower as well as higher cut off frequency is almost constant for both designs but the impedance bandwidth is increases for the circular ring antenna. The impedance matching has also been improved in the entire UWB band. Therefore, the optimized dimension of the feed width is taken as $W_{f}=2 \mathrm{~mm}$.

\subsubsection{Return loss variation with ground plane width $(W)$ :}

It is observed that lower the higher cut off frequency of the both designs are almost same when width of ground is varying from $40 \mathrm{~mm}$ to $44 \mathrm{~mm}$. Further, the lower impedance matching has been obtained (see Fig.6) between 3-4GHz. Whereas in case of circular ring design the lower cut off frequency slightly shifted to lower side at the same dimensions and impedance matching has been improve in the frequency band $3-4 \mathrm{GHz}$. Therefore the optimized dimension of the ground is select at $\mathrm{W}=42 \mathrm{~mm}$.

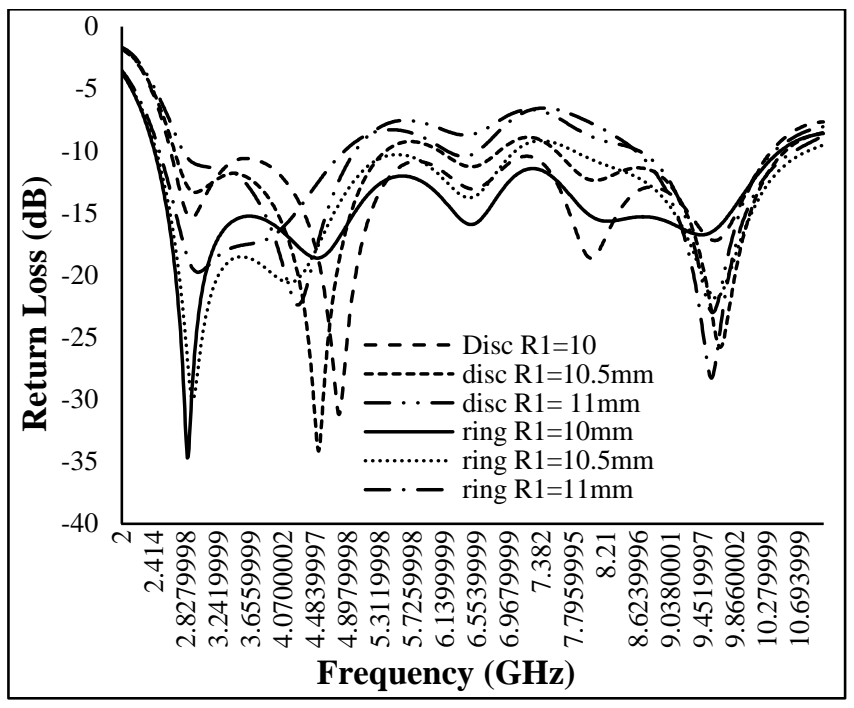

Fig.3. Effect of outer radius $\left(R_{1}\right)$ of both of circular disc and circular ring antenna

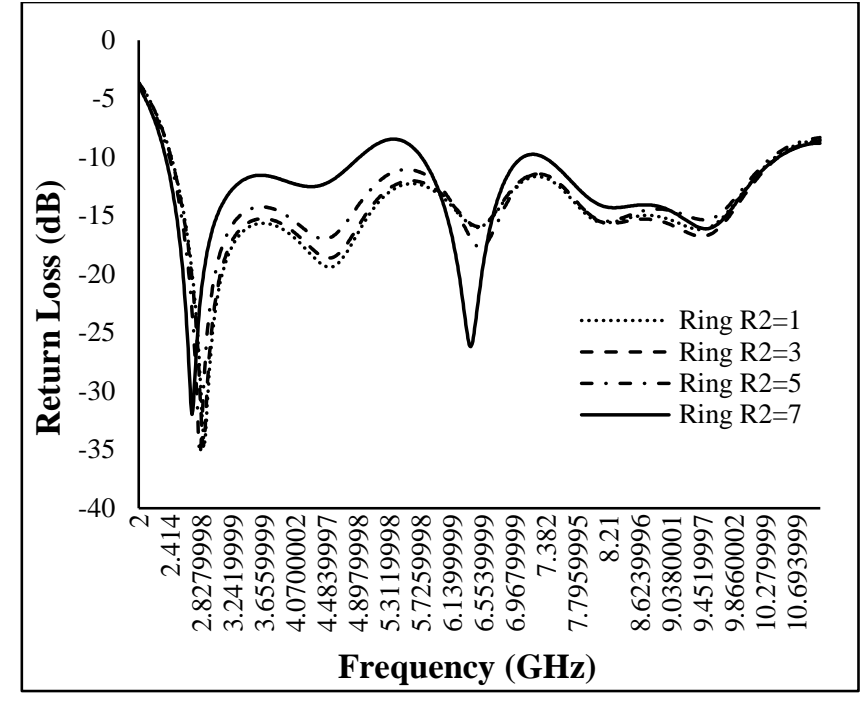

Fig.4. Simulated outcomes by varying inner radius $\left(R_{2}\right)$ of circular ring antenna

\subsubsection{Return Loss variation with ground length $\left(L_{g}\right)$ :}

Return loss variation for circular disc and circular ring antennas has been shown in Fig.7. It has been seen observe that when length of the rectangular ground is varying from $19 \mathrm{~mm}$ to $21 \mathrm{~mm}$ lower cut off frequency shifted toward the lower side and higher resonant frequencies are shifted toward the higher side, Therefore, the impedance matching is not good at $L_{g}=19 \mathrm{~mm}$ and $21 \mathrm{~mm}$ for both the antennas. Further, better impedance matching has been achieved at $L_{g}=20 \mathrm{~mm}$ for circular ring antenna.

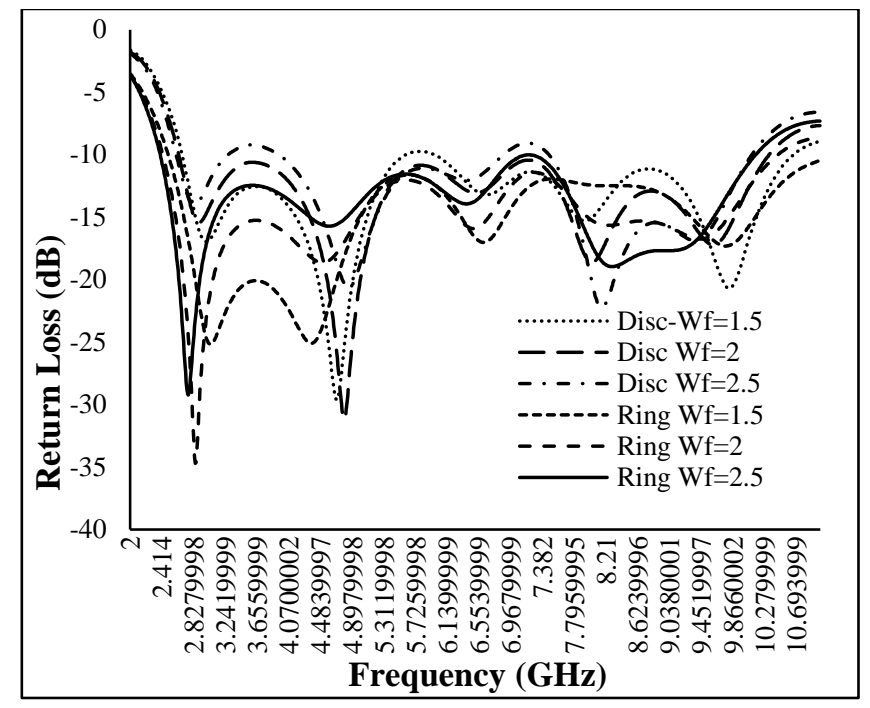

Fig.5. Simulation return loss of micro-strip line $W_{f}$ for circular disc and circular ring antenna 


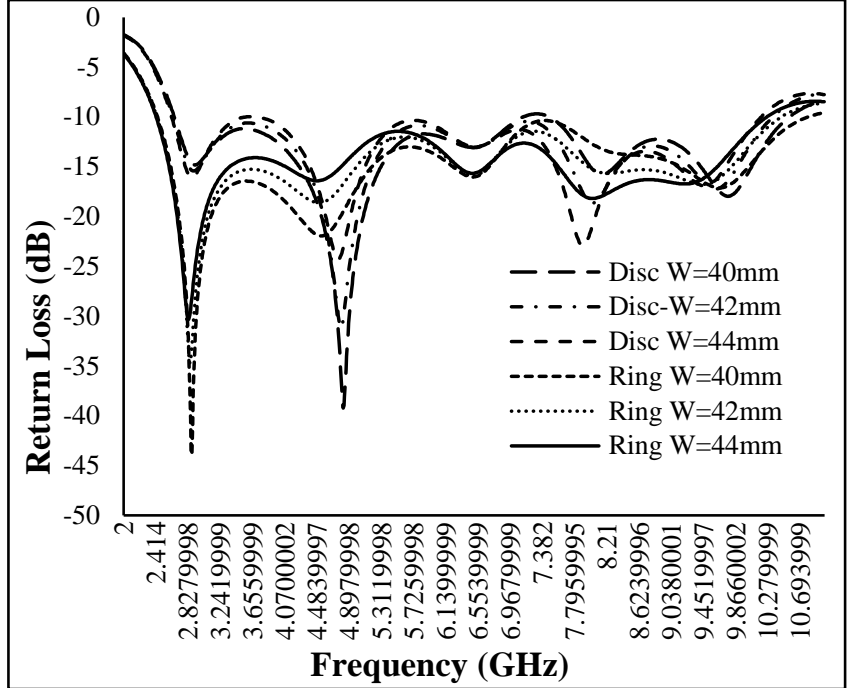

Fig.6. Effect of width of antenna $W$ on return loss of the circular disc and circular ring antenna

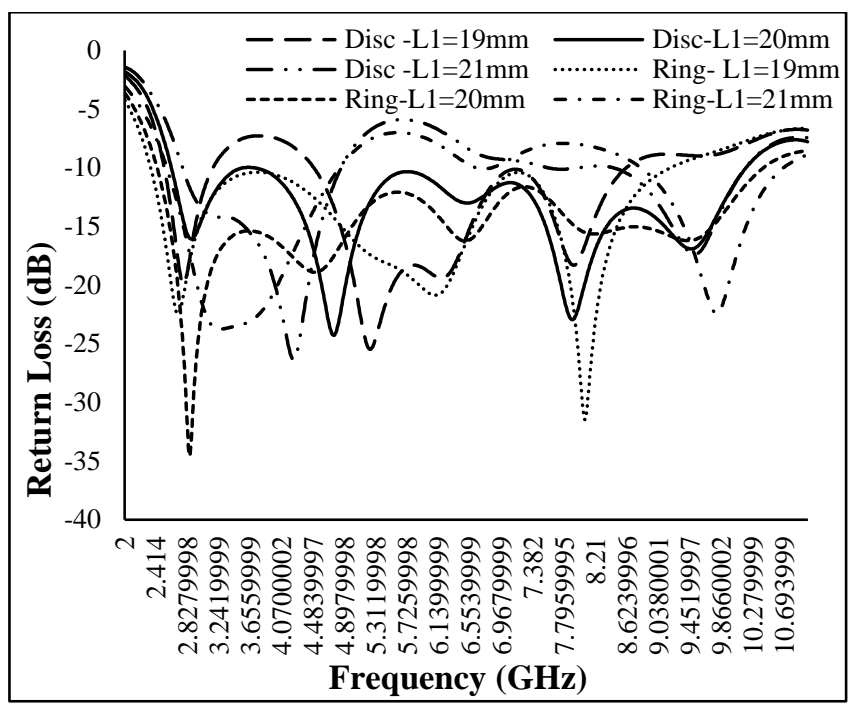

Fig.7. Effect of ground length $L_{g}$ on return loss of the circular disc and circular ring antenna

The parametric performance analysis of the proposed design has been given in Table. 2 in terms of fractional bandwidth, return loss, resonance frequencies.

Table.2. Parametric performance analysis with variations of $R_{1}$, $R_{2}, W_{f}, W$ and $L_{g}$

\begin{tabular}{|c|c|c|c|c|c|}
\hline $\begin{array}{c}\text { Circular } \\
\text { Ring } \\
\text { Antenna }\end{array}$ & $\begin{array}{c}\text { Paramete } \\
\text { rs } \\
\text { Variation } \\
(\mathbf{m m})\end{array}$ & $\begin{array}{c}\text { Resonance } \\
\text { Frequencies } \\
(\mathbf{G H z})\end{array}$ & $\begin{array}{c}\text { Return Loss } \\
(\mathbf{d B})\end{array}$ & $\begin{array}{c}\text { Freque } \\
\text { ncy } \\
\text { Band } \\
\mathbf{( G H z})\end{array}$ & $\begin{array}{c}\text { Imped } \\
\text { ance } \\
\mathbf{B W} \\
(\%)\end{array}$ \\
\hline \multirow{2}{*}{$\begin{array}{c}\text { Outer } \\
\text { Radius of } \\
\text { Patch }\end{array}$} & $R_{1}=10$ & $\begin{array}{c}2.8 / 4.5 / 6.4 / \\
8.2 / 9.4\end{array}$ & $\begin{array}{c}-34.7 /-18.7 /- \\
15.9 /-15.7 /-17\end{array}$ & $\begin{array}{c}2.4- \\
10.4\end{array}$ & 125 \\
\cline { 2 - 6 } & $R_{1}=10.5$ & $\begin{array}{c}2.9 / 4.1 / 6.4 / 9 \\
.6\end{array}$ & $\begin{array}{c}-30 /-20.7 /-13.8 /- \\
21.8\end{array}$ & $2.4-7$ & 97 \\
\cline { 2 - 6 } & $R_{1}=11$ & $2.9 / 6.4 / 9.5$ & $-19.7 /-10.4 /-28.3$ & $2.4-4.8$ & 66 \\
\hline & $R_{2}=1$ & $\begin{array}{c}2.8 / 4.5 / 6.5 / 8 \\
.2 / 9.4\end{array}$ & $-34.7 /-19.6 / 16.6 /-$ \\
$15.6 /-16.3$ & $2.4-$ & 10.4 & 125 \\
\hline
\end{tabular}

\begin{tabular}{|c|c|c|c|c|c|}
\hline \multirow{3}{*}{$\begin{array}{c}\text { Inner } \\
\text { Radius of } \\
\text { Patch }\end{array}$} & $R_{2}=3$ & $\begin{array}{c}2.8 / 4.5 / 6.4 / 8 \\
.2 / 9.4\end{array}$ & $\begin{array}{c}-34.7 /-18.7 /- \\
15.9 /-15.7 /-17\end{array}$ & $\begin{array}{l}2.4- \\
10.4\end{array}$ & 125 \\
\hline & $\mathrm{R}_{2}=5$ & $\begin{array}{c}2.8 / 4.4 / 6.5 / 8 \\
.2 / 9.4\end{array}$ & $\begin{array}{c}-35.4 /-17.0 /- \\
17.7 /-15.8 /-15.4\end{array}$ & $\begin{array}{l}2.4- \\
10.2\end{array}$ & 123 \\
\hline & $\mathrm{R}_{2}=7$ & $\begin{array}{c}2.6 / 4.4 / 6.3 / 9 \\
.5\end{array}$ & $\begin{array}{c}-31.7 /-12.5 /- \\
26.5 /-16.1\end{array}$ & $\begin{array}{l}7.3- \\
10.3\end{array}$ & 34 \\
\hline \multirow{3}{*}{$\begin{array}{l}\text { Feed } \\
\text { Width of } \\
\text { Micro- } \\
\text { strip Line }\end{array}$} & $W_{f}=1.5$ & 3/4.3/6.6/9.7 & $\begin{array}{c}-25.3 /-25.1 /-17 /- \\
17.4\end{array}$ & $\begin{array}{l}2.4- \\
11.2\end{array}$ & 129 \\
\hline & $W_{f}=2$ & $\begin{array}{c}2.8 / 4.5 / 6.4 / 8 \\
.2 / 9.4\end{array}$ & $\begin{array}{c}-34.7 /-18.7 /- \\
15.9 /-15.7 /-17\end{array}$ & $\begin{array}{l}2.4- \\
10.4\end{array}$ & 125 \\
\hline & $W_{f}=2.5$ & $\begin{array}{c}2.7 / 4.5 / 6.5 / 9 \\
.6\end{array}$ & $\begin{array}{c}-29.3 /-15.9 /- \\
14.1 /-19\end{array}$ & $2.3-7.1$ & 102 \\
\hline \multirow{3}{*}{$\begin{array}{l}\text { Width of } \\
\text { the } \\
\text { Antenna }\end{array}$} & $W=40$ & $\begin{array}{c}2.8 / 4.5 / 6.5 / 9 \\
.6\end{array}$ & $\begin{array}{c}-44.1 /-22 /-16.3 /- \\
17.3\end{array}$ & $\begin{array}{l}2.4- \\
10.7\end{array}$ & 126 \\
\hline & $W=42$ & $\begin{array}{c}2.8 / 4.5 / 6.4 / 8 \\
.2 / 9.4\end{array}$ & $\begin{array}{c}-34.7 /-18.7 /- \\
15.9 /-15.7 /-17\end{array}$ & $\begin{array}{l}2.4- \\
10.4\end{array}$ & 125 \\
\hline & $W=44$ & $\begin{array}{c}2.8 / 4.4 / 6.4 / 8 \\
\quad / 9.2\end{array}$ & $\begin{array}{c}-30.6 /-16.5 /- \\
15.7 /-18.4 /-16.9\end{array}$ & $\begin{array}{l}2.4- \\
10.2\end{array}$ & 123 \\
\hline \multirow{3}{*}{$\begin{array}{l}\text { Ground } \\
\text { Length }\end{array}$} & $L_{g}=19$ & 2.6/6.1/8.0 & $-22.3 /-20.6 /-31.5$ & $3.7-7.1$ & 62 \\
\hline & $L_{g}=20$ & $\begin{array}{c}2.8 / 4.5 / 6.4 / 8 \\
.2 / 9.4\end{array}$ & $\begin{array}{c}-34.7 /-18.7 /- \\
15.9 /-15.7 /-17\end{array}$ & $\begin{array}{l}2.4- \\
10.4\end{array}$ & 125 \\
\hline & $L_{g}=21$ & $3.2 / 6.7 / 9.8$ & $-23.7 /-10 /-22.5$ & $2.5-4.8$ & 63 \\
\hline
\end{tabular}

\subsection{VSWR}

The mismatch power between antenna and feed line has been defined by VSWR of any antenna. The comparative simulated VSWR plot of circular disc and circular ring antenna has been shown in Fig.8. The value of VSWR of circular ring antenna is lower than reference antenna which is 1.5. Therefore, the proposed antenna gives the better impedance matching between micro-strip feed line and radiator.

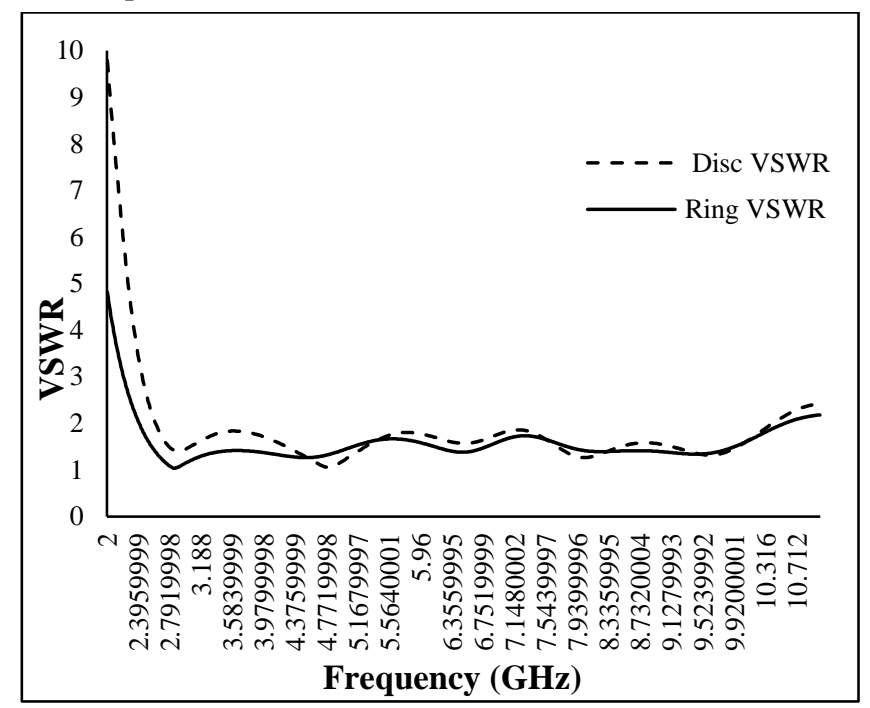

Fig.8. Simulated VSWR variation for circular disc and circular ring antenna

\subsection{GAIN}

The simulated gain variation of proposed antenna and circular disc antenna has been shown in the Fig.9. It can be seen that; the proposed antenna gives slightly higher gain than circular disc antenna. Hence simulated maximum peak gain is $6.5 \mathrm{dBi}$ for 
circular ring antenna whereas maximum peak gain is $6.4 \mathrm{dBi}$ for circular disc antenna at the same frequencies $(9.4 \mathrm{GHz})$. Therefore, both antennas give the identical gain in frequency band of $3-9.5 \mathrm{GHz}$.

\subsection{GROUP DELAY}

The comparative simulated group delay for circular disc and circular ring antenna are shown in Fig.10. The maximum group delay variation for circular disc is $3 \mathrm{~ns}$ whereas the group delay variation circular ring antenna is up to $1 \mathrm{~ns}$. Therefore, the group delay variation of proposed UWB antenna show a linear phase when compare to a circular disc antenna.

\subsection{SURFACE CURRENT DISTRIBUTIONS}

The simulated surface current distribution of the proposed antenna and circular disc antennas are shown in Fig. 11 at $2.8 \mathrm{GHz}$ and $6.5 \mathrm{GHz}$ resonant frequencies, respectively. It is observed that the current is mainly concentrates on the edges of circular patch, MS feed line and ground plane which increases the path length of the current due to their symmetrical defected structures. Hence the resonant frequencies of circular disc antenna are decreases when compared with circular disc antenna due to increase the path length of current.

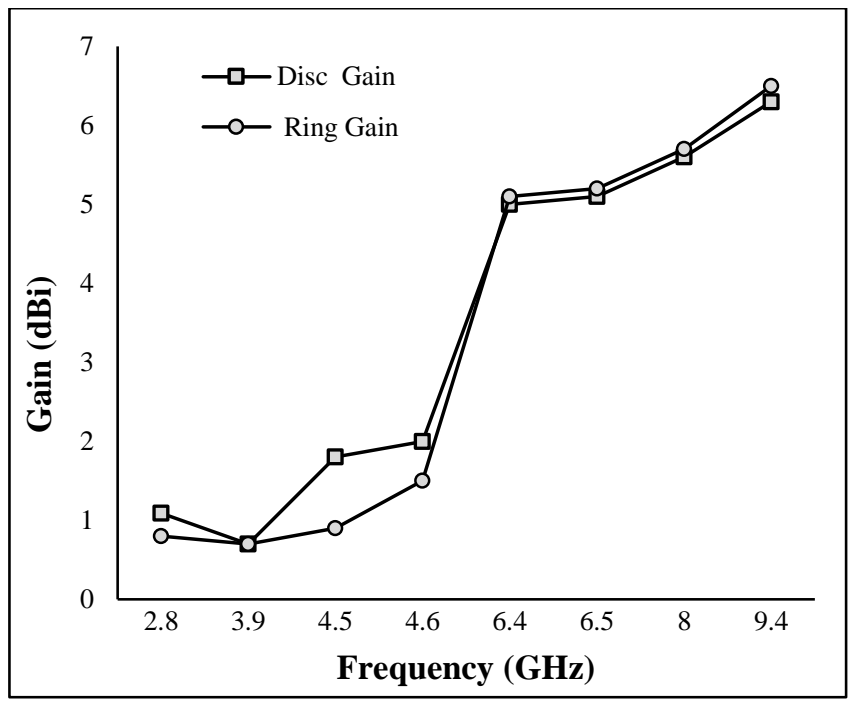

Fig.9. Simulated gain of circular disc and circular ring antenna

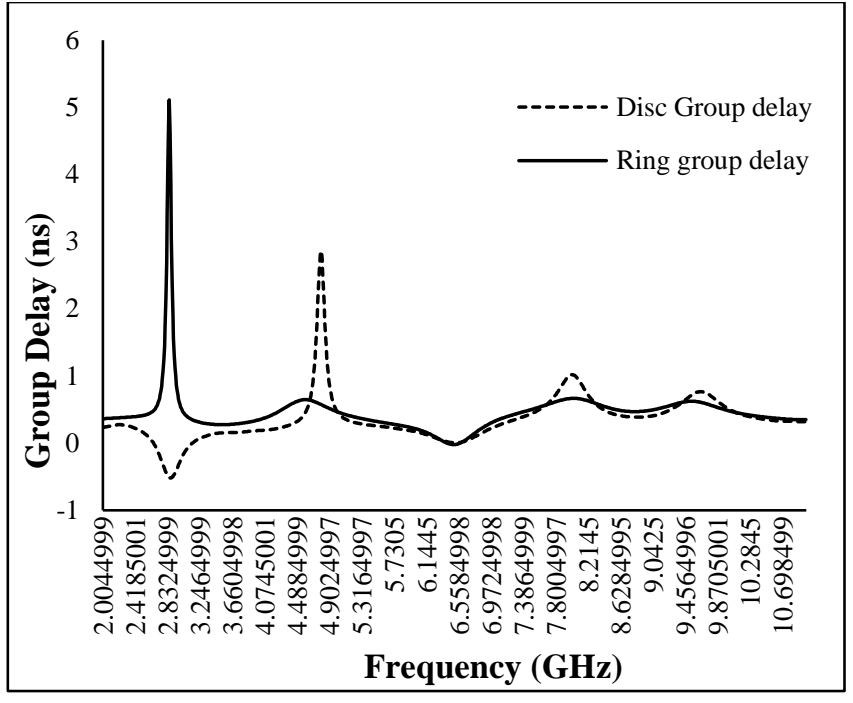

Fig.10. Simulated group delay of circular disc and circular ring antenna

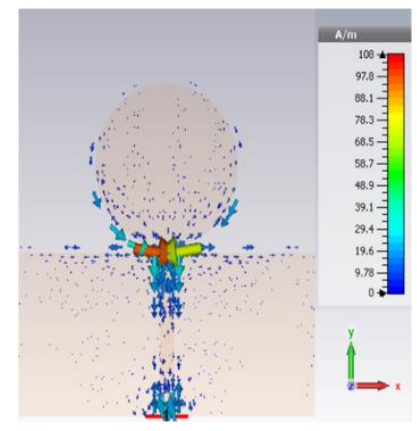

(a)

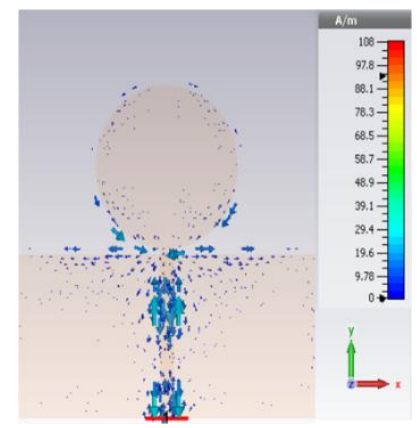

(c)

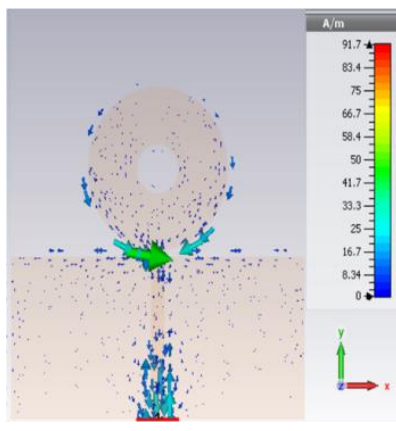

(b)

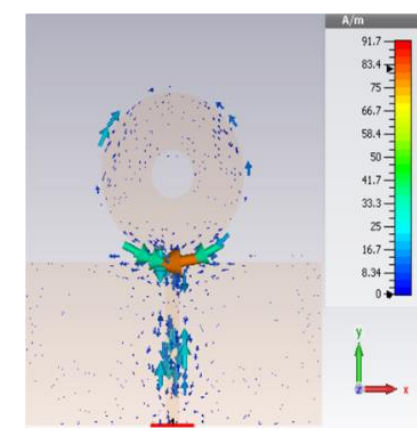

(d)
Fig.11. Simulated surface current distribution (a), (c) for circular disc antenna and (b), (d) for circular ring antenna at different resonant frequencies, respectively

\section{MEASURED RESULTS AND DISCUSSIONS}

Performance of the proposed antenna has been affected mainly due to inner and outer radius, feed width and separation between ground and patch. The detailed comprehensive study has been discussed in section 3 . Therefore, proposed circular ring antenna has been fabricated with optimized dimensions as given in Table. 1 and measurement has been carried out on Vector Network Analyzer (VNA) as shown in Fig.12. It can be seen in Fig.13 
measured and simulated results are approximately same. The minor variations in measurements is due to soldering of SMA connector and atmospheric conditions: a) $f=2.8 \mathrm{GHz}$, b) $f=$ $2.8 \mathrm{GHz}$, c) $f=6.5 \mathrm{GHz}$ and d) $f=6.5 \mathrm{GHz}$.

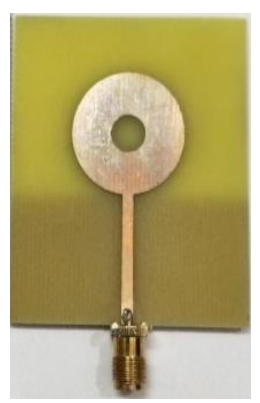

(a)

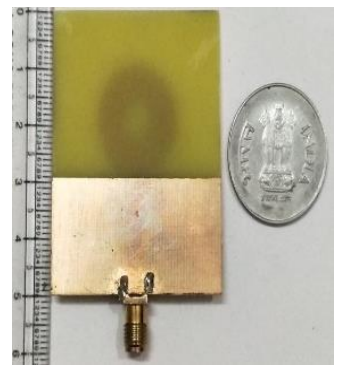

(b)

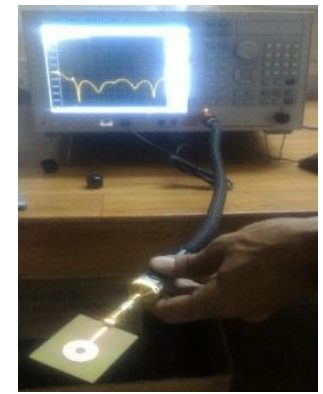

(c)

Fig.12. Fabricated circular ring antenna and measurement setup

(a) Front view; (b) Back view; (c) Proposed antenna measurement setup

It has been observed that $120 \%$ fractional bandwidth is achieved by measurements in the frequency band of $2.6-10.4 \mathrm{GHz}$ below $-10 \mathrm{~dB}$. Further, the simulated radiation pattern of circular disc and circular ring antenna are shown in Fig.14 at different resonant frequencies the calculated half power beam width (HPBW) or $3 \mathrm{~dB}$ angular width of circular disc is $81,62.6,50.9$ at $2.8 \mathrm{GHz}, 6.5 \mathrm{GHz}$ and $8 \mathrm{GHz}$ resonant frequencies, respectively. Further the angular width of proposed antenna is 93.5, 49.6 and 34.2 at same resonant frequencies. Therefore, the radiation pattern of the circular disc antenna shows a bidirectional pattern whereas the proposed antenna gives a directional radiation pattern. Hence the design antenna is suitable for radar system.

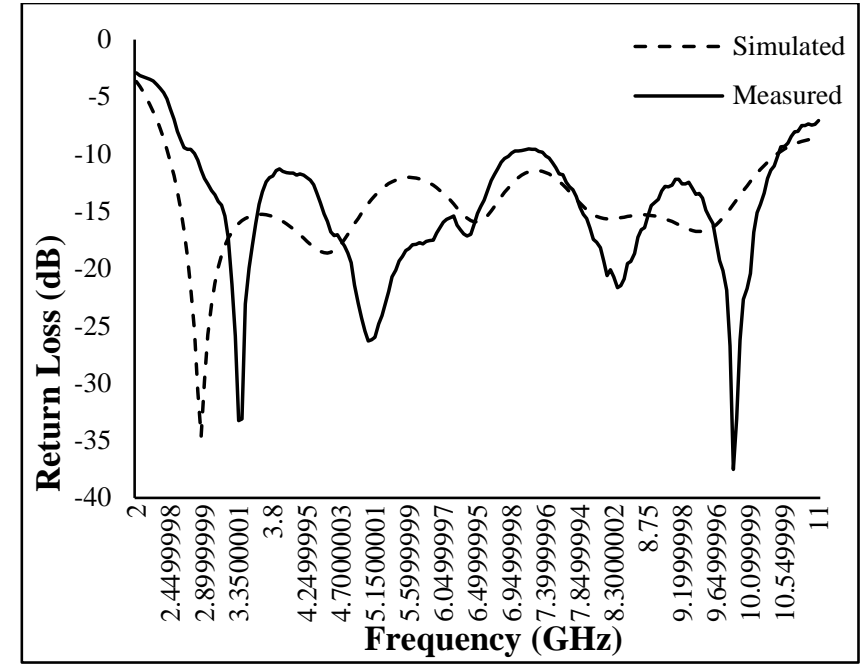

Fig.13. Measured and simulated return loss $\left(S_{11}\right)$ plot of the fabricated antenna

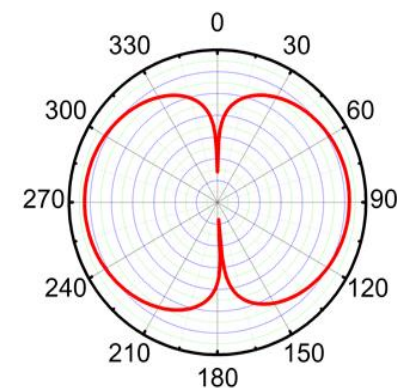

(a) $f=2.8 \mathrm{GHz}$

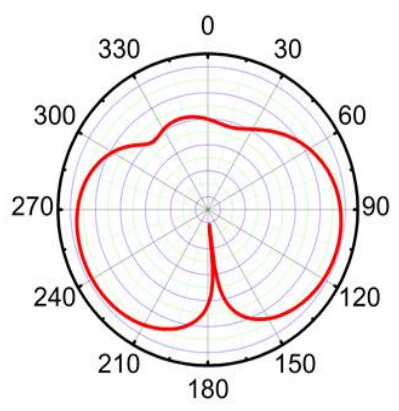

(b) $f=6.5 \mathrm{GHz}$

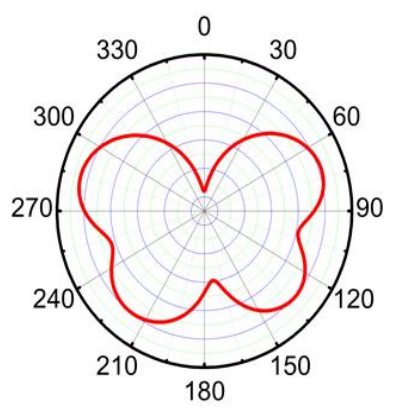

(f) $f=8 \mathrm{GHz}$

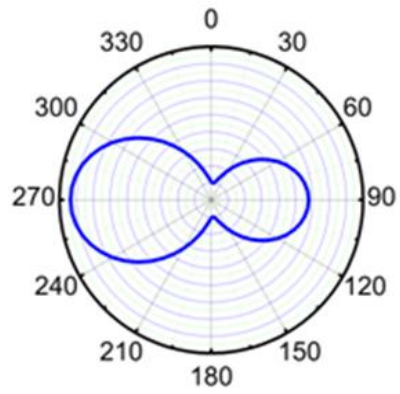

(d) $f=2.8 \mathrm{GHz}$

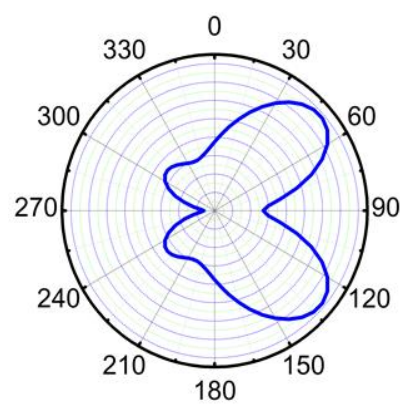

(e) $f=6.5 \mathrm{GHz}$

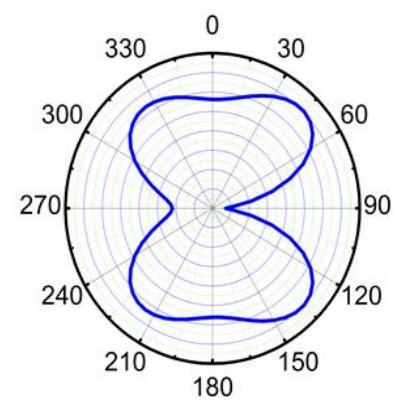

(g) $f=8 \mathrm{GHz}$
Fig.14. Simulated radiation pattern (a), (b), (c) for circular disc, (d), (e), (f) for circular ring antenna 
Further the performance analysis of circular disc and circular ring antennas are given in Table. 3 in terms of bandwidth, gain, impedance bandwidth, half power beam width and applications. Furthermore, the comparative analysis of the proposed antenna and earlier reported antennas in literature have also been given in Table.4.

Table.3. Calculated and simulated parameters of circular disc and circular ring antenna

\begin{tabular}{|c|c|c|}
\hline Antenna Parameter & $\begin{array}{c}\text { Circular Disc } \\
\text { (Reference } \\
\text { Antenna) }\end{array}$ & $\begin{array}{l}\text { Circular } \\
\text { Ring } \\
\text { Antenna }\end{array}$ \\
\hline \multirow{5}{*}{$\begin{array}{l}\text { Resonance Frequency } \\
\qquad(\mathrm{GHz})\end{array}$} & 2.8 & 2.8 \\
\hline & 4.7 & 4.5 \\
\hline & 6.5 & 6.4 \\
\hline & 8 & 8.2 \\
\hline & 9.6 & 9.4 \\
\hline -10dB Bandwidth $(\mathrm{GHz})$ & $2.6-10.3$ & $2.4-10.4$ \\
\hline Gain $(\mathrm{dBi})$ & 6.4 & 6.5 \\
\hline Impedance Bandwidth (\%) & 119 & 125 \\
\hline $\mathrm{HPBW}\left({ }^{\circ}\right)$ & $81 / 66 / 62 / 50 / 105$ & $\begin{array}{c}93 / 123 / 49 / 32 \\
/ 32\end{array}$ \\
\hline Applications & $\begin{array}{l}\text { Military, } \\
\text { Precision } \\
\text { Location and } \\
\text { Tracking }\end{array}$ & $\begin{array}{c}\text { Medical } \\
\text { Imaging and } \\
\text { Ground } \\
\text { Penetrating } \\
\text { Radar }\end{array}$ \\
\hline
\end{tabular}

Table.4. Comparative performance analysis of proposed antenna and previously reported antennas in literature.

\begin{tabular}{|c|c|c|c|c|}
\hline Reference & $\begin{array}{c}\text { Antenna Size } \\
\left(\mathbf{m m}^{2}\right)\end{array}$ & $\begin{array}{c}\text { Frequency } \\
\text { band (GHz) }\end{array}$ & $\begin{array}{c}\text { Fractional } \\
\text { Bandwidth } \\
(\boldsymbol{\%})\end{array}$ & $\begin{array}{c}\text { Gain } \\
(\mathbf{d B i})\end{array}$ \\
\hline$[21] 2010$ & $\begin{array}{c}0.7 \lambda_{0} \times \lambda_{0} \\
(31.2 \times 44.2)\end{array}$ & $3.6-10.1$ & 94 & $\mathrm{NA}$ \\
\hline$[22] 2012$ & $\begin{array}{c}0.6 \lambda_{0} \times 0.7 \lambda_{0} \\
(30 \times 32)\end{array}$ & $3.1-10.6$ & 109 & 5 \\
\hline$[23] 2013$ & $\begin{array}{c}1.6 \lambda_{0} \times 1.6 \lambda_{0} \\
(50 \times 50)\end{array}$ & $8-12$ & 40 & 6.4 \\
\hline$[24] 2014$ & $\begin{array}{c}0.5 \lambda_{0} \times \lambda_{0} \\
(30 \times 30)\end{array}$ & $4-7.2$ & 57 & 3 \\
\hline$[25] 2015$ & $\begin{array}{c}0.8 \lambda_{0} \times 0.8 \lambda_{0} \\
(32 \times 32)\end{array}$ & $6.4-9.5$ & 39 & 8.2 \\
\hline$[26] 2016$ & $\begin{array}{c}1.3 \lambda_{0} \times 1.3 \lambda_{0} \\
(50 \times 50)\end{array}$ & $4.1-11.5$ & 95 & 8.4 \\
\hline$[27] 2016$ & $\begin{array}{c}0.5 \lambda_{0} \times 0.5 \lambda_{0} \\
(30 \times 30)\end{array}$ & $2.8-8.9$ & 104 & 6.3 \\
\hline$[29] 2016$ & $\begin{array}{c}1.1 \lambda_{0} \times 1.2 \lambda_{0} \\
(55 \times 56)\end{array}$ & $1.58-11.54$ & 151 & 5.5 \\
\hline$[30] 2017$ & $\begin{array}{c}0.6 \lambda_{0} \times 0.5 \lambda_{0} \\
(30 \times 26.4)\end{array}$ & $2.87-10.4$ & 113 & $\mathrm{NA}$ \\
\hline$[31] 2017$ & $\begin{array}{c}1.6 \lambda_{0} \times 1.6 \lambda_{0} \\
(108 \times 108)\end{array}$ & $3.1-6$ & 63 & 9.7 \\
\hline Proposed \\
Antenna & $\begin{array}{c}0.9 \lambda_{0} \times \lambda_{0} \\
(42 \times 50)\end{array}$ & $2.4-10.4$ & 125 & 6.5 \\
\hline
\end{tabular}

\section{CONCLUSIONS}

In this paper, a circular ring UWB antenna having partial ground plane has been presented and compared with circular disc antenna. To achieves better impedance matching the optimized dimensions of the proposed antenna have been carried out, fabricated and tested. The design antenna archives $125 \%$ fractional bandwidth in the UWB band of $2.4-10.4 \mathrm{GHz}$. The circular ring antenna operates into five resonant modes of 2.8, 4.5, $6.4,8.2$ and $9.5 \mathrm{GHz}$ in the specified UWB band. The design antenna gives good agreement between measured and simulated results. Further, the antenna size, bandwidth, gain characteristics and fractional bandwidth of the proposed antenna have also been compared with earlier reported antennas in literature.

\section{REFERENCES}

[1] Federal Communications Commission, Available at: https://en.wikipedia.org/wiki/Federal_Communications_Co mmission.

[2] S. Sadat, M. Fardis, F. Geran and G. Dadashzadeh, "A Compact Microstrip Square Ring Slot Antenna for UWB Applications", Progress in Electromagnetics Research, Vol. 67, pp. 173-179, 2001.

[3] K.G Jangid, Ajay Tiwari, Vijay Sharma, V.S Kulhar, V.K Saxena and D. Bhatnagar, "Circular Patch Antenna with Defected Ground for UWB Communication with WLAN Band Rejection", Defence Science Journal, Vol. 66, No. 2, pp. 162-167, 2016.

[4] L. Liu, S.W. Cheung, R. Azim and M.T. Islam, "A Compact Circular-Ring Antenna for Ultra-Wideband Applications", Microwave and Optical Technology Letters, Vol. 53, No. 10, pp. 2283-2288, 2011.

[5] M.L. Meena and Mithilesh Kumar, "Partially Hexagonal Ground Plane UWB Elliptical Patch Antenna", International Journal of Electronics and Communication Engineering and Technology, Vol. 4, No. 7, pp. 66-73, 2013.

[6] Liang Xu, Y ong-Iun Luo and Zhen-yu Xin, "A Compact Monopole Antenna for Bluetooth and UWB applications with Dual Band Notched Characteristics", Proceedings of International Workshop on Microwave and Millimeter Wave Circuits and System Technology, pp. 50-53, 2013.

[7] A. Bhattacharya, B. Roy, M. Islam, S.K. Chowdhury and A.K. Bhattacharjee, "An UWB Monopole Antenna with Hexagonal Patch Structure Designed using Particle Swarm Optimization Algorithm for Wireless Applications", Proceedings of IEEE International Conference on Microelectronics, Computing and Communications, pp. 1-5, 2016.

[8] Y.S. Santawani and S.R. Suralkar, "A Compact Hexagonal Shaped Patch Antenna for UWB Applications using CPW Feed", Proceedings of International Conference on Pervasive Computing, pp. 1-5, 2015.

[9] M.L. Meena and Mithilesh kumar, "Eight Shape Microstrip Patch Antenna with Crescent Slot for Wideband Applications", Proceedings of $5^{\text {th }}$ IEEE International Conference on Computational Intelligent and Communication Network, pp. 49-54, 2013.

[10] Y.S. Hu, M. Li, G.P. Gao, J.S. Zhang and M.K. Yang, "A Double-Printed Trapezoidal Patch Dipole Antenna for UWB 
Applications with Band-Notched Characteristic", Progress in Electromagnetics Research, Vol. 103, pp. 259-269, 2010.

[11] P.A. Nawale and R.G. Zope, "Design and Improvement of Microstrip Patch Antenna Parameters using Defected Ground Structure", International Journal of Engineering Research and Applications, Vol. 4, No. 6, pp. 123-129, 2014.

[12] K. Abhishek, R. Sharma and S. Kumar, "Bandwidth Enhancement using Z-Shaped Defected Ground Structure for a Microstrip Antenna", Microwave and Optical Technology Letters, Vol. 55, pp. 2251-2254, 2013.

[13] Gagandeep Kaur, Geetanjali Singla and Simarjit Kaur, "Design of Wideband Microstrip Patch Antenna using Defected Ground Structure for Wireless Applications", International Journal of Advanced Research in Computer Science and Software Engineering, Vol. 3, No. 10, pp. 2327, 2013.

[14] K.A. Ashwini, M.V. Kartikeyan and A. Patnaik, "Efficiency Enhancement of Microstrip Patch Antenna with Defected Ground Structure", Proceedings of International Conference on Recent Advances in Microwave Theory and Applications, pp. 729-773, 2008.

[15] G. Singh, R. Rajni and R.S. Momi, "Microstrip Patch Antenna with Defected Ground Structure for Bandwidth Enhancement", International Journal of Computer Applications, Vol. 73, No. 9, pp. 14-18, 2013.

[16] R.A. Fayadh, H.A. Fadhil, F. Malek and N. Saudin, "Design of Ultra Wideband Rectangular Microstrip Notched Patch Antenna", Proceedings of IEEE International Conference on Control Systems, Computing and Engineering, pp. 408412, 2013.

[17] A. Rajagopalan, G. Gupta, A.S. Konanur, B. Hughes and G. Lazzi, "Increasing Channel Capacity of an Ultra wideband MIMO System using Vector Antennas", IEEE Transactions on Antennas and Propagation, Vol. 55, No. 10, pp. 28802887, 2007.

[18] M.H. Hoang, H.P. Phan, Q.H. Dien and D.L. Nguyen, "Design and Experimental Study of An Ultra-Wideband Radar System", Proceedings of IEEE International Conference on Advanced Technologies for Communications, pp. 64-68, 2014.

[19] Kenny Seungwoo and Ahmed A. Kishk, "UWB Antenna with Single or Dual Band-Notches for Lower WLAN Band and Upper WLAN Band", IEEE Transactions on Antennas and Propagation, Vol. 57, No. 12, pp. 3942-3950, 2009.

[20] Y.D. Dong, W. Hong, Z.Q. Kuai and J.X. Chen, "Analysis of Planar Ultra Wideband Antenna with on Ground Slot Band-Notched Structures", IEEE Transactions on Antennas and Propagation, Vol. 57, No. 7, pp. 1886-1893, 2009.

[21] J.R. Panda, P. Kakumanu and R.S. Kshetrimayum, "A Wideband Monopole Antenna in Combination with a UWB
Microwave Band-Pass Filter for Application in UWB Communication System", Proceedings of Annual IEEE India Conference, pp. 186-189, 2010.

[22] Abhik Gorai, Shashank Verma, Anirban Karmakar and Rowdra Ghatak, "Sierpinski Fractal Binomial Tapered Planar Monopole Antenna for UWB Communication", Proceedings of IEEE International Conference on Computers and Devices for Communication, pp. 1853-1859, 2012.

[23] R. Sharma, A. Kandwal and S.K. Khah, "Wideband DGS Circular Ring Microstrip Antenna Design using Fuzzy Approach with Suppressed Cross Polar Radiations", Progress in Electromagnetics Research C, Vol. 42, pp. 177190, 2013.

[24] S. Rawat and K.K. Sharma, "A Compact Broadband Microstrip Patch Antenna with Defected Ground Structure for C-Band Applications", Central European Journal of Engineering, Vol. 4, pp. 287-292, 2014.

[25] J.A. Ansari, S. Verma, M.K. Verma and N. Agrawal, "A Novel Wide Band Microstrip Line-Fed Antenna with Defected Ground for CP Operation", Progress in Electromagnetics Research C, Vol. 58, pp. 169-181, 2015.

[26] M.L. Meena, Mithilesh Kumar, Girish Parmar and R.S. Meena, "Design Analysis and Modeling of Directional UWB Antenna with Elliptical Slotted Ground Structure for Applications in C \& X Bands", Progress in Electromagnetic Research C, Vol. 63, pp. 193-207, 2016.

[27] P. Zhao, Dongling He, and Xiaodong Huang. "Compact UWB Antenna using Multiple Radiation Arms loaded with Circular Patches", Proceedings of IEEE International Conference on Microwave and Millimeter Wave Technology, pp. 149-153, 2016.

[28] A.M. Abbosh, M. E. Bialkowski, J. Mazierska and M.V. Jacob, "A Planar UWB Antenna with Signal Rejection Capability in the $4 / 6 \mathrm{GHz}$ Band", IEEE Microwave and Wireless Components Letters, Vol. 16, No. 5, pp. 278-280, 2006.

[29] K. Anusudha and M. Karmugil, "Design of Circular Microstip Patch Antenna for Ultra Wide Band Applications", Proceedings of IEEE International Conference on Control, Instrumentation, Communication and Computational Technologies, pp. 304-308, 2016.

[30] M. Dhanvijay, P. Anuradha and R.K. Gupta, "Compact Circular Ring-Shaped Monopole UWB MIMO Antenna”, Proceedings of IEEE $3^{\text {rd }}$ International Conference on Sensing, Signal Processing and Security, pp. 104-107, 2017.

[31] S. Patil, Rajiv Gupta and Shilpa Kharche, "Gain improvement of lower UWB monopole antenna using FSS layer", Proceedings of International Conference on IEEE Nascent Technologies in Engineering, pp. 1-5, 2017. 